\title{
UNA MORAL DEL CANTO: EL PENSAMIENTO POETICO DE GONZALO ROJAS
}

Nacemos y desnacemos en lo efímero, recuerda Gonzalo Rojas en unos versos de Oscuro (Caracas: Monte Avila Editores, 1977). Y no obstante esta lucidez, se dispone con avidez a nombrar el mundo y a descubrir «el largo parentesco de las cosas», como igualmente expresa desde la breve página en prosa que abre el volumen. La distancia entre aquella conciencia existencial de la humana transitoriedad y esta otra apetencia de integración y fijeza por la poesía trata Rojas de salvarla con su voluntad de sumergirse en una fecundante sustancia originaria que él designa como oscuro y oscuridad. Regresar de esos fondos, que a pesar de su aura semántica no han de identificarse con el mundo de lo críptico o inescrutable, provisto de los hallazgos más luminosos allí encontrados: tal es el sentido de su oficio ciego, de ese ejercicio de diamante en que para él, como poeta, consiste el acto de dar nombre al mundo y descifrar el misterio de su unidad primera y esencial. $\mathrm{Y}$ estas intuiciones suyas -oficio ciego, ejercicio de diamante-, que aparecen así literalmente en el poema primero del libro, nos obligan a reparar en las sugerencias implícitas en la imagen simbólica del diamante - luz y dureza, brillo y resistenciacomo opuestas a las de tenebrosidad y tanteo - ceguera - de su mismo oficio. Entre los varios núcleos posibles de su pensamiento poético, el que sumariamente acaba de describirse es aquel de donde estas notas pretenden partir.

De las tres secciones en que Rojas organizó bajo categoría temática el material de Oscuro, es la primera («Entre el sentido y el sonido»), si no la única provechosa, sí la de mayor interés para el tema que aquí se intenta explorar. Mas habrá de ponerse énfasis en que sólo mirando también al poeta erótico-reflexivo del apartado segundo ("Qué se ama cuando se ama») y al poeta crítico-moral y denunciativo del tercero («Los días van tan rápidos»), todo lo cual es a la vez Gonzalo Rojas, se podrá alcanzar un esbozo cabal de su entendimiento y práctica de la poesía. Por- 
que si bien la aproximación que aquí se planea opera por concentración, tal imperativo no puede comportar exclusión, y ello debe quedar escrupulosamente sentado. Habrá que aclararlo más en evitación de malentendidos: aun cuando por razones de su motivación central la historia no tiene cabida en estos apuntes, esa historia no queda nunca abolida en la poesía de Oscuro. Ni la «historia del cuerpo», donde el franco erotismo carnal no disuelve la sugestión del amor como trascendencia, como lugar de encuentro de ese mismo cuerpo y el espíritu, sino que la refuerza; ni la historia amputada del hombre en la pesadilla criminal de la sociedad moderna rubricada por un testigo de muy aguda sensibilidad ética. La advertencia se hacía indispensable.

Mas en la personal ordenación de Oscuro escuchamos primero a su autor meditar visionariamente sobre la poesía y hablar después de su vida y de la vida. Coincidiendo aquí con una actitud básica del surrealismo - y sin apurar filiaciones en este punto-, Rojas ha afirmado su decisión de asumir «la poesía como conducta», y de qué modo quiso siempre «más que escribir, vivir como poeta». Para él, inquirir sobre la poesía será una forma más de replantearse los problemas de la existencia y el ser, correspondiéndose a la vez con aquella demanda definitoria de la modernidad que exige del poeta un desdoblamiento vigilante en creador y pensador crítico de la poesía. El resultado de ese proceso en Rojas, por lo que tiene de auténtica disciplina de conocimiento propio y no de «deber» mostrencamente aprendido, es de una originalidad y una hondura impresionantes.

Ya se indicó la zona nutricia de donde emana esta poesía: lo oscuro, sentido en tanto que realidad hermosa, viva, centelleante, guerrero, metáfora del silencio creador y del origen -como se la califica en el poema «Oscuridad hermosa»-. Allí palpita la escondida pero benéfica luz que el poeta ha de afanarse por aprehender, pues también se sabe criatura solar y proclama más de una vez en un verso clave que el sol es la única semilla. Lo oscuro no es en Rojas, como en el Neruda de las Residencias, signo de osarios y de muertes, sino llave del más iluminador misterio. Una palabra le sirve para dar corpórea visualidad a esta paradojal identificación. Y es la primera que recuerda. "Voy corriendo - escribe- en el viento de mi niñez en ese Lebu tormentoso, y oigo, tan claro, la palabra 'relámpago' - ¡iRelámpago, relámpago!-. Y voy volando en ella y hasta me enciendo en ella todavía». Por eso la prodiga en sus versos, pues el relámpago no es sino fulgor instantáneo y repetido nacido de la sombra en la tormenta y recortado sobre ella. $Y$ así le servirá para expresar la fusión de la luz en lo oscuro, la instantaneidad y lo continuo, el deslumbramiento y la permanencia. Las recurrencias de la voz relámpago, 
como imagen de la vida y aun de la eternidad, han de ser numerosísimas en Oscuro.

Esta misma polaridad se erige como la central y resumidora de las muy variadas formas de dualismo que conceden su nerviosidad a estos poemas: la matería y el Espíritu, el instante y la Eternidad, el accidente y lo Absoluto, lo Hondo y lo Alto, la historia y el Origen, lo visible y lo invisible, la nada y el Todo, la palabra y el silencio, lo diverso y lo Unico. Y Rojas no teme, como tampoco nuestros modernistas, destacar muchas veces la categoría trascendente con esa mayúscula magnificadora que aquéllas tanto necesitaban. Las dualidades indicadas por servidumbre de la condición humana quedan grabadas como oposiciones; pero a la vez se intuye que la secreta armonía entre ellas no sólo será posible, sino que es presentida como un seguro adviento, y aun que su búsqueda actúa como la dinamo mayor en la aventura del espíritu. Mas el hombre no puede percibirlas en su inmediatez, sino como modos de escisiones, de desgarramientos. A su través, el poeta, que a sí mismo (con Pitágoras ya a la vista) se ha llamado geómetra menesteroso de la exactitud, pasa aguijado por su hambre y cargado de sus interrogaciones. $Y$ al no caber para éstas ninguna respuesta plausible de los poderes racionales, esas preguntas han de ser erguidas y clavadas en un ámbito superior: el de lo misterioso y sagrado. Sin ambages: en el ámbito de lo religioso. Reclamar aquel «largo parentesco de las cosas» o adivinar en otro verso esta especie de beso que las aproxima [a las cosas], es una empresa religiosa, si bien y únicamente en su sentido orginario: de religare, fusión de lo disperso, retorno a la unidad.

Rojas mismo ha brindado pistas explícitas para esta adscripción de su pensamiento poético. En una entrevista reciente ha sostenido: «La poesía se me da en la órbita de lo sagrado...». Y para definir su concepción al respecto acude al término numinoso, acuñado por Rudolf Otto en su libro Das Heilige, de 1917, que en su versión española, titulada Lo santo, aparecida en 1925, Rojas leyó en su juventud '. Y con ese mismo término rotula el poema que sirve de apertura al libro, «Numinoso», y el cual, por esta posición, aconseja algún detenimiento en él. Otto creó esa voz derivándola de numen (dios, divinidad, inspiración o majestad divina) para designar con ella la esencia de lo sagrado, limpiándola de espúreos añadidos como son las interpretaciones racionales de la religiosidad y la equiparación de ésta con la ética. Mysterium tremendum: he aqui, para el pensador alemán, el atributo mayor del objeto numinoso. Algo inefable

${ }^{1}$ Hemos manejado la última versión de este libro al inglés: Studies on the Holy, 2nd edition (New York: Oxford University Press, 1970). 
o inexpresable (implicado en el sustantivo mysterium), ante lo cual la única reacción humana posible (suscitada por el adjetivo tremendum) es la de una veneración o respeto reverencial, un «estremecimiento» que está más allá de todo miedo o temor y de cualquier sentimiento subjetivo o jerárquico de «criatura» y dependencia. Lo numinoso sería aquello, y Rudolf Otto lo señala como ejemplo propicio, que en la adoración cristiana genuina invade poderosamente al hombre religioso y le hace volverse a lo alto con las palabras «santo, santo, santo». La numinoso lleva adherido una percepción de majestas, majestad - no infrecuente en Rojas: recuérdese su poema "Contradanza», donde valora de majestuoso el sentimiento supremo de lo Unico-, y esa majestad provoca en el alma la sensación enriquecedora de su energía trascendente. De aquí, concluye el autor de Lo santo, que en la experiencia numinosa lo inicialmente aprehendido como «plenitud de poder» quede transmutado en quien gozosamente la sufre en «plenitud de ser».

El arribo a esta plenitud requiere una anulación del "irrisorio Yo» (así lo concibe Rojas) y condiciona un sinfín de negaciones, como las que se imponen en la etapa místico-purgativa de la noche oscura de los sentidos. Y para allí llegar - y se pasa ya al texto anunciado: "Numinoso»-, el poeta emprenderá una serie creciente de rechazos como en esta primera: no brilla / el orgullo en estas cuerdas, no cantamos, no / somos augures de nada... Ni soberbia ni destino profético: sólo la humildad que ha de ir preparando la irrupción final de lo numinoso. Es todavía la ascesis purificadora, que más adelante hace surgir otra secuencia del mismo signo:

\author{
no \\ encanto, no repetición \\ por la repetición, que gira y gira \\ sobre \\ sus espejos, no \\ la elegancia de la niebla, no el suicidio...
}

Cuatro proposiciones negativas que (con un anchísimo margen para el érror: aceptarlo es abrazar la ambigüedad riquísima de la poesía) podrían desde nuestro acercamiento traducirse así y respectivamente: no la poesía como práctica encantatoria (¿Altazor en su vuelo, antes de la caída?), ni los juegos borgianos que dan la ilusión de continuidad o permanencia, ni la vaguedad neblinosa y distanciadora con la que el simbolista se aleja refinadamente de la realidad, ni el autosacrificio del poeta que entrañan el voluntario homicidio del lenguaje y la aniquilación de la forma. 
Consumado de ese modo el despojamiento total, hay ya sólo ese vacío donde el poeta y el místico coinciden. El precario haber que resta se expresa también desde la profesión de la humildad. Así se lee en el verso primero de la última estrofa: Míseros los errantes, eso son nuestras silabas, tiempo... Aire - sílabas- y tiempo, nada más. La presencia del aire adquiere en Rojas una extraordinaria plurivalencia simbólica que, de poder documentar aquí, comprobaría que aquél se le presenta ante todo como imagen del impulso creativo, capaz de proferir con su levísimo soplo al Verbo, que es el origen de todo y también como hálito vital: delgado pero único medio de sernos y poder. Así vio también Nietzsche al aire: como la materia misma de nuestra libertad. $\mathrm{Y}$ el otro elemento de la misérrima posesión, el tiempo, lo percibe Rojas como el resultado - la causa de nuestra dispersión, sobre la cual ejercerá el espíritu su nostálgica acción unificadora. Nada hasta ahora en el poema que se va glosando ha sido insinuado como señal del mysterium tremendum del objeto numinoso; pero precisamente por ello los dos versos últimos son recibidos como un sobrecogedor aviso de que el poeta lo ha avistado y sentido. $Y$ hacia su majestad se alza, desde la desposesión, y con aquellas mismas palabras de veneración que recordaba Rudolf Otto. Estos son esos dos versos finales del poema: Aire y Tiempo / dicen santo, santo, santo. En tal altura climática ante lo innombrable e innombrado, las dos débiles realidades del hombre - el aire, el tiempo- se transfiguran, alcanzan su «plenitud de ser», y quedan resaltadas con esas mayúsculas que se guardan para las entidades y los momentos absolutos.

Que el pensamiento poético de Gonzalo Rojas, y atacándolo ahora desde un ángulo de observación más comprensivo, admite una lectura de cariz trascendente, se revela por descansar aquél en una interrelación de nociones de esa misma índole trascendente, cuya raíces nos llevarían a las esencias poéticas más firmes del modernismo. Ello no se opone al hecho de que su lenguaje descubra a un poeta enriquecido por las experiencias de la vanguardia y cercano a la visión espiritual profunda del surrealismo por su adhesión a la básica tríada Poesía-Amor-Libertad (que casi respectivamente cantan las tres secciones de Oscuro). A explicar este enraizamiento genérico del ideario poético de Rojas en el correspondiente del modernismo, sin implicar por ello innecesarios e inexistentes calcos de la letra o expresión modernista, va dirigida la segunda parte de este ensayo, pero esa parte, por las naturales limitaciones de tiempo (o de espacio), ha de ser aquí sacrificada. Mas para que la conclusión de esta ponencia, que es lo que más destacado queda en su título ("Una moral del canto»), no advenga de modo arbitrario, será de alguna utilidad una apretadísima síntesis de lo que en dicha parte segunda se contiene. Para mayor clari- 
dad van a continuación enumerativamente los puntos esenciales desarrollados con su normal extensión en la versión original de estas páginas ${ }^{2}$.

1) Alusión, como punto de partida, al hecho de que fueron los modernistas en la tradición hispánica quienes adquieren una plena conciencia del destino del poeta como auscultador y transmisor del ritmo o armonía y del lenguaje del cosmos (del Universo); con algunas ilustraciones al respecto desde Martí y, casi programáticamente, desde Darío.

2) Elaboración de un cuadrilátero de fundamentos noéticos sobre los que se levanta el pensamiento de Rojas, asombrosamente afín en este punto al del modernismo. Tal cuadrilátero funcionaría así: del apoyo en el Número y en el Ritmo (o los sucedáneos connotativos de éste: Armonía, Analogía, Música) a la intuición del Origen y la revelación de la Unidad. Ratificación textual de estas cuatro nociones en Oscuro.

3) Análisis más pormenorizado de tres piezas en tal sentido magistrales de Rojas: "Acorde clásico», "Remando en el ritmo» y, lo que pareciera casi increíble, «El fornicio», una de las de más intenso erotismo del libro perteneciente a su sección segunda. Aprovechamiento en estos análisis de algunas ideas útiles sobre el ritmo y el pitagorismo en tanto que soportes de la visión poética del modernismo (procedentes de Octavio Paz, Ricardo Gullón, Raymond Skyrme, Guillermo Sucre e Ivan A. Schulman ${ }^{3}$ ); y de postulaciones coincidentes, ya encaminadas con especificidad a la poesía de Rojas, de dos de los recién citados (Paz y Sucre), así como de Juan Liscano, José Emilio Pacheco, Fernando Charry Lara (contenidas en artículos, notas y reseñas publicadas a raíz de la aparición de Oscuro) y en partícular del crítico y poeta chileno Floridor Pérez en el estudio más completo e inédito hasta la fecha sobre dicho libro.

Para que no queden demasiado en abstracto las consideraciones que aquí tan prietamente se resumen, léase uno de los poemas recién mencionados: «Acorde clásico». Es muy breve, pero suficiente. $Y$ obsérvese su ideal central: cómo el ritmo original, pues de nada anterior emerge, va

2 Dicha versión original está destinada al libro Homenaje a Luis Leal, cuya edición preparan en estos momentos los profesores Donald W. Bleznick y Juan O. Valencia.

${ }^{3} \mathrm{He}$ aquí la procedencia bibliográfica de los trabajos indirectamente aludidos en el texto: Octavio Paz, El arco y la lira, 2. ${ }^{2}$ ed. (México: Fondo de Cultura Económica, 1967); Ricardo Gullón, «Pigatorismo y modernismo», en Estudios críticos sobre el modernismo, ed. Homero Castillo (Madrid: Gredos, 1968); Raymond Skyrme, Rubén Dario and the Pythagorean Tradition (Gainesville: The University of Florida Presses, 1975); Guillermo Sucre, La máscara, la transparencia (Caracas: Monte Avila Editores, 1975); Ivan A. Schulman, «Modernismo, revolución y el pitagorismo en la obra de Martí», Casa de las Américas, 13, núm. 73 (1972). 
rigiendo con su vitalidad creadora la vida total del cosmos y la vida del hombre en el cosmos:

Nace de nadie el ritmo, lo echan desnudo y llorando como el mar, to mecen las estrellas, se adelgaza para pasar por el latido precioso de la sangre, fluye, fulgura en el mármol de las muchachas, sube en la majestad de los templos, arde en el número aciago de las agujas, dice noviembre detrás de las cortinas, parpadea en esta página.

Y ya por ese camino se impone recordar estos pocos versos mágicamente tensos entre el desnudo erotismo por un lado y el oído alerta a la música trascendente por el otro. Y nótese cómo el poeta encuentra aún espacio para notariar el nombre del legendario mentor espiritual que a esto último impele. Pertenecen esos versos a otro de los poemas indicados: «El fornicio»:

me

arrebatara el opio de tu piel hasta lo ebúrneo de otra pureza, oyera cantar a las esferas estallantes como Pitágoras, te lamiera...

4) Erección de una nueva tríada, culminatoria en el pensamiento poético de Rojas en su vertiente trascendente sobre los conceptos de Unidad, Belleza y Eternidad -y rastreo en este punto de particulares afinidades con el Valle-Inclán de La lámpara maravillosa y el Juan Ramón Jiménez de Espacio. Aclaración del personal sentido con que Rojas encara la intuición de la eternidad, como transfiguración del instante o como síntesis dialéctica a la que se llega desde la conciencia de lo fugaz y el ansia de lo permanente. Oscuro se abre con estos versos de Grabiela Mistral, a los que el poeta añade por su cuenta les interrogaciones: ¿Será esto la eternidad / que aún estamos como estábamos? Y se cierra con esta declaración del propio Rojas: "Pero la eternidad es esto mismo».

5) Referencia ocasional a otras aproximaciones - entre ellas la de René de Costa, con su interés por los elementos «antipoéticos» en ciertas zonas del lenguaje de Oscuro- que exploran esta poesía desde perspectivas distintas y complementarias a la que por razón de su tema se ha seguido en este ensayo ${ }^{4}$.

" René de Costa, «Gonzalo Rojas Between the Poem and the Antipoem», Latin American Literary Review, núm. 12 (primavera-verano 1978). 
Y ahora sí puede arribarse ya a la conclusión esperable. El pensamiento poético de Gonzalo Rojas se mueve bajo este designio: salvar, sin negarlos, los desdoblamientos y fracturas del hombre en su condición real y temporal, y restaurar por el ritmo y la analogía la plenitud del ser en la unidad primaria del origen. $\mathrm{Y}$ una poesía sostenida sobre tal pensamiento, donde nada lejos se siente el ahincado anhelo común de los modernistas, ha de tornarse canto, humilde pero firme ejercicio de invocación y de celebración: invocación de aquella unidad, celebración del mundo - uva a uva de su racimo, como se dice en el comentado poema «Numinoso»-. No elocuencia ni diapasón retórico: no himno levantado al milagro cotidiano de la Creación (el Cántico de Jorge Guillén), ni oda «elemental" a sus criaturas más sencillas (el Neruda correspondiente). Estrictamente canto, visionario y llano a un tiempo, emitido por una voz que prefiere y sabe ajustar su emoción, a la vez que reclama el maravilloso don de la armonía y defiende su deber (su derecho) a cantar. Porque, a propósito de Ezra Pound, y hablándoles a los poetas, advierte Rojas, y él cumple fielmente su advertencia: cántico / hombres de poca fe, piensen en el cántico.

Se está así, al menos como credo poético sobre el que la historia escribirá después sus correcciones, en las antípodas de todo desgarrón que conspire contra el ritmo y la música del verso, a lo que pudiera llegarse mediante la intromisión voluntaria del coloquialismo prosaico y la abrupta desmembración «experimental» de las estructuras lingüísticas. E1 mismo Rojas considera a los poetas actuales que juegan verso y prosa de un modo semejante -y cita a dos de ellos: Ernesto Cardenal y Nicanor Parra - como alineados dentro de tal sentido en la orilla opuesta a la suya. Mas cuando el sentimiento del tiempo y el dolor humano ante la injusticia social y la muerte se enseñorean de su conciencia, la insalvable ironía (que puede alcanzar el nivel de la más afilada sátira) clavará los dientes roedores y aniquiladores en su ensueño analógico, raíz de su necesidad del canto, y los resortes verbales de la expresión reflejarán condicionadamente allí la aspereza de ese sañudo ataque. Vulnerable entonces, pues la historia en sus concreciones más burdas no deja de corroer nunca el sueño del espíritu, no se quebrará del todo, sin embargo, esa afincada vocación del autor. Ni éste cejará en afirmarla: «Me vuelvo - ha dichoa la vieja edad en que los poetas cantaban». Y esa moral del canto a que se obliga es la lección más personal que desde su hermosa poesía ofrece Gonzalo Rojas en el panorama de la lírica hispanoamericana de hoy.

Hunter College,

José Olivio Jiménez

City University of New York. 